\title{
Imperfect Recall: In So Many Words Tom Denlinger
}

This text briefly introduces the photographic work of Chicago-based artist and photographer Tom Denlinger, with a focus on his series Imperfect Recall (2006).

Keywords: Pergamon Museum, Notebaert Natural History Museum, Art Institute of Chicago, landscape, diorama, memory

My work addresses the interaction of landscape, culture and photography that shapes our collective vision of the environment. I strive to interfere with this vision by redefining historically recognized images and narratives within the context of my studio practice.

In a series of work begun in 2006, Imperfect Recall, I alter landscape-related images found in museums such as the Art Institute of Chicago, the Pergamon Museum in Berlin and the Chicago Academy of Sciences Notebaert Natural History Museum by introducing them into my own dioramas and re-photographing them.

In an exhibition at the Notebaert Museum in Spring 2008, also called Imperfect Recall, I used a $4 \times 5$ view camera to collect images from landscape dioramas that were constructed by the museum from historical data to represent views of the Chicago area before it was settled. I projected those images into partial environments that I built in my studio in response to the area that surrounds the museum, and then used the view camera to photograph the result. For example in "Coyote Family Values (detail C)" one is confronted with a trash-strewn pond in which one can dimly make out an image of a family of coyotes in a long-lost plains environment. Two of the photographs that 
I made of the Museum's Coyote/Plains diorama are exhibited with the above-mentioned photograph to make a triptych entitled "Coyote Family Values."

Similarly in my work with the Art Institute of Chicago and the Pergamon Museum in Berlin I project images from each institution onto fragmentary landscapes that I have recreated from the environs of each museum-archive. In particular for "Around the Art Institute: Struth" and "Around the Art Institute: Josephson" I selected Thomas Struth's photograph of museum patrons gazing at Gustave Caillebotte's painting of nineteenth century Paris, and Ken Josephson's "postcard view" of the cruise ship New York State on an anonymous body of water, because of each artist's displacement of a scene or image into another setting, as well as for their efforts to insert themselves in some fashion into the artwork.

As in the Notebaert Museum, the Pergamon constructs its dioramas from historical documents and archeological data. But contrary to the Notebaert, it eschews a polychromed depiction of a historical backdrop in favor of a white arena of architectural blocks, walls and corridors that frame and foreground the ancient, painted depictions of the artifacts themselves. This has a net effect of making the entire museum into a single diorama within which the objects are situated, as if the Ishtar gate, the Pergamon Altar and the other archeological sites represented were close neighbors in the ancient world. I confiscate these representations and re-position them within a contemporary, fragmented, museum island.

Each museum-archive assembles a collection of images and artifacts in order to present a broadly integrated historical view. In Imperfect Recall I intervene with iconic 


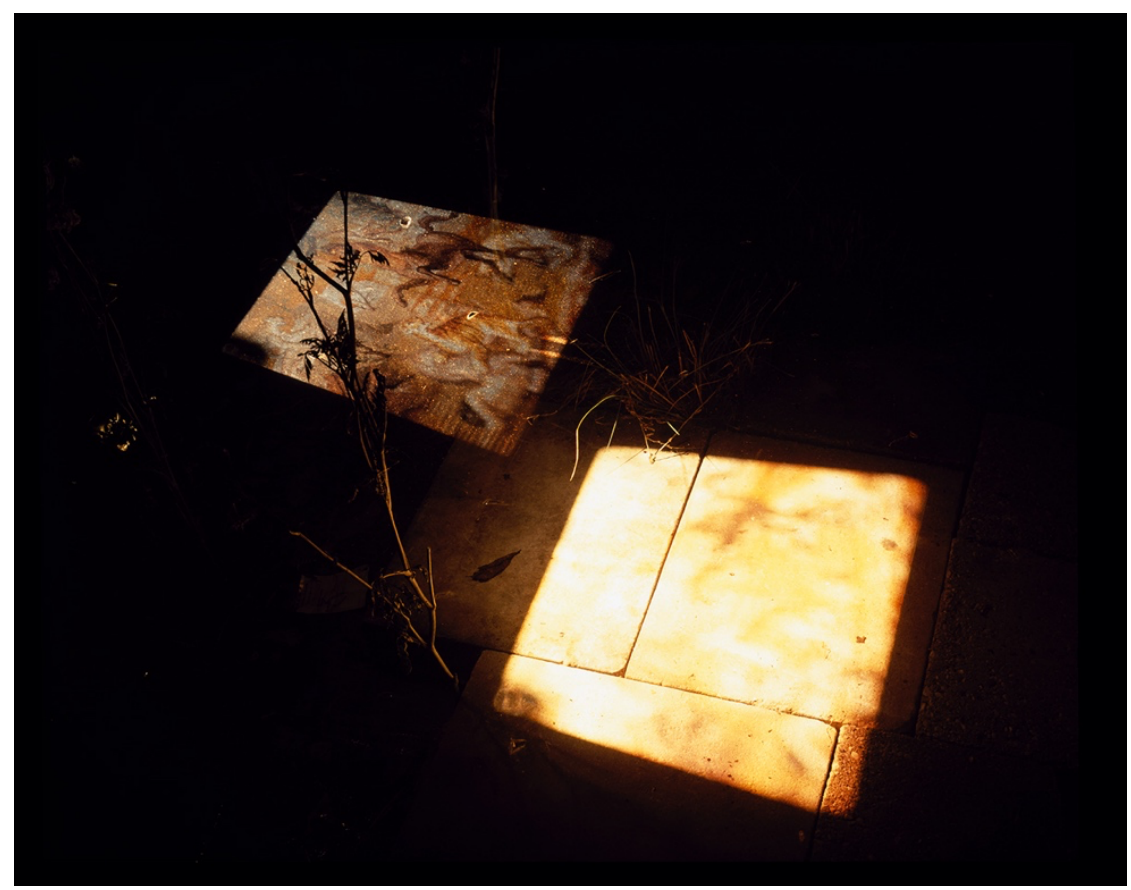

Imperfect Recall: Around the Pergamon: Centaur Mosaic 2006 40" x 50"

Courtesy of the artist, (c) Tom Denlinger 


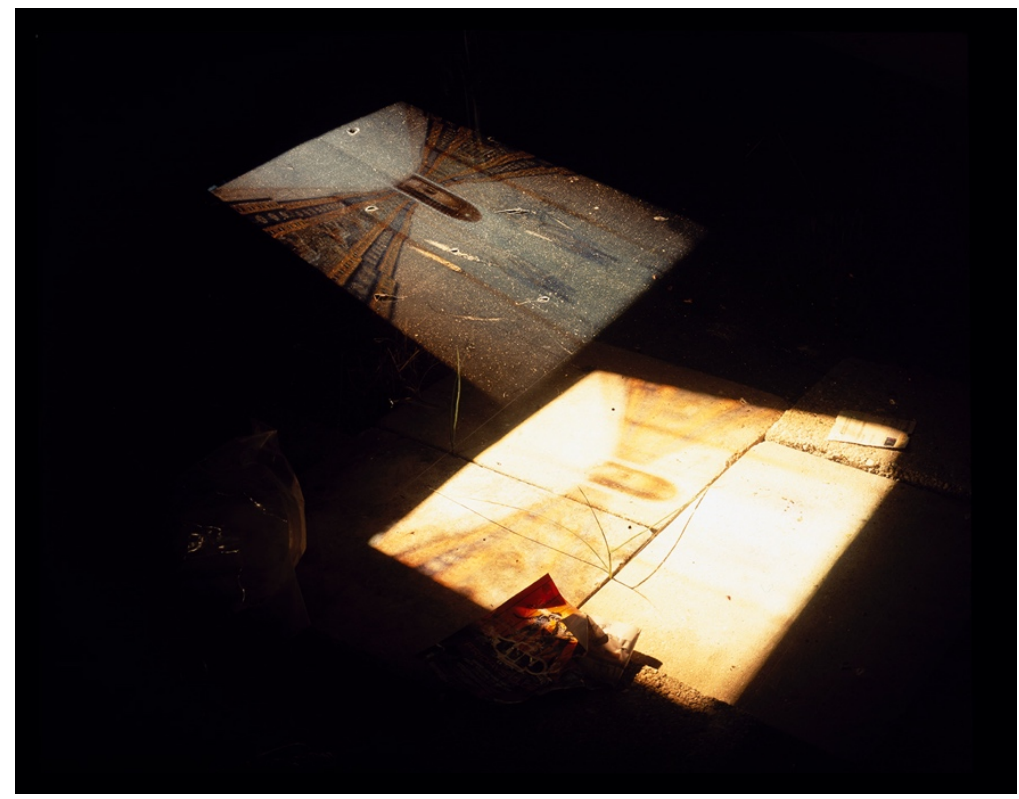

Imperfect Recall: Around the Pergamon: Ishtar

Corridor $200640 "$ x 50"

Courtesy of the artist, (c) Tom Denlinger

representations by the Pergamon Museum, the Art Institute of Chicago, and the Notebaert Natural History Museum by inserting my own peculiar and inconsistent settings into their perfect order to simultaneously connect with and disrupt that unified idea. I provide an alternative reading in which imperfect memory and artifact translate and interfere with the historicized diorama, breaking the patina of archival "total" memory of the Museum, and indicating instead a vision of a discontinuous and polymorphous present. 